\title{
CHARACTERIZING THE WORK ENVIRONMENT OF SKIDDER OPERATORS: EVALUATION OF TEMPERATURE AND RELATIVE HUMIDITY CONDITIONS
}

\author{
Marina V. MARCU ${ }^{1}$ Bogdan F. HUSĂU-ROMAN ${ }^{1}$ \\ Stelian A. BORZ ${ }^{1}$
}

\begin{abstract}
Skidding is one of the commonly used technical options to extract wood from felling to landing. As such, several studies have been carried out to evaluate its effectiveness in terms of economics, environmental impact, and ergonomics. Most ergonomic studies have addressed the exposure to noise and vibration, and less effort has been devoted towards the evaluation of the skidder operators' working environment. To our knowledge, the exposure to variability in temperature and humidity has not yet been studied for skidding operations. This study aimed at evaluating the variability of such microclimate parameters and at comparing them to their counterparts recorded in the forest environment. Based on comparative datasets collected in November 2020, our results indicate that skidder operators might endure a significant variation in temperature and relative humidity during operations, which in turn may affect their health. Compared to the forest environment, the differences in temperature and relative humidity were evident, contrasting and occurred in short periods of time, as an effect of the skidding operations and mobility on increased distances and of a considerable altitudinal range. It is likely for such variability to also come from the work behavior of different operators. Given the results and the season in which the data was collected, as well as other constraints of the study, further studies should be carried out to separate the operation time from the rest and meal breaks, to evaluate the variability in microclimate throughout all seasons, to control the state of the cabin doors, and to solve the problem of control data mobility so as to accurately reflect the outdoor conditions for each location a skidder may work on during skidding operations.
\end{abstract}

Key words: skidding, work environment, temperature, relative humidity.

\footnotetext{
${ }^{1}$ Department of Forest Engineering, Forest Management Planning and Terrestrial Measurements, Faculty of Silviculture and Forest Engineering, Transilvania University of Brasov, Şirul Beethoven 1, 500123, Brasov, Romania; Correspondence: Stelian A. Borz; email: stelian.borz@unitbv.ro.
} 


\section{Introduction}

Wood harvesting is commonly seen as a complex process [14] which is typically implemented to convert standing trees into logs and to deliver them from the felling area to the landing. Both the complexity and the performance of wood harvesting could be described and characterized by the interaction between a relatively high number of technical options which can be implemented, variability of the operational environment in which they are deployed, and the variability brought by the experience and performance of people who operate such systems.

Among other options, skidding is commonly used to extract wood from felling areas to landing. Typically, skidders are rubber-tired ground-based machines propelled by internal combustion engines which are designed to enable wood handling and transportation functions [14]. Recent studies [10], [13], [19] have found that such forest equipment accounts for an important share of the technical options used to extract wood around the world. However, updating the skidder fleet by purchasing new machines was found to run at a low rate [19], which may mean that old versions of the machines are kept and used in operations for many years. Coupled with the general knowledge on the forest operations ergonomics and safety [16], such a dynamic of the skidder use market may raise several questions about the quality of the human work environment in skidding operations. On the one hand, this is because the fleet ageing alters its designed functionality and may expose the workers to increasing doses of harmful factors. On the other hand, having an old fleet in operations prevents the integration of the latest technology so as to be able to better control and fine-tune the work environment of the operators (i.e., the machine's cabin). Such problems are of concern for the sustainability of forest operations which is placing a great emphasis on the prevention of adverse health effects [7] and on the quality of work environment [12].

By design, skidders are commonly operated from within a cabin although some supportive work requires stepping out of it for certain amounts of time. In addition, the use of internal combustion engines exposes their operators to various doses of noise and vibration during the operations. It was found that in many cases these doses exceed the permitted thresholds [16], as well as the fact that the exposure may depend on the variability of local operational conditions, particularly that of the extraction distance [15]. In fact, an increased share of engine use within a day could be the main factor generating increasing exposure to various harmful factors. Arguably, great emphasis has been placed on the quantification and modelling of exposure to factors such as noise and vibration in forest operations [16] including skidding [15], because such factors have been commonly associated with severe professional disorders such as hearing loss and various cardio-vascular and musculoskeletal problems. However, a healthy work environment stands for more than controlling the exposure to noise and vibration. A particular problem which to our knowledge has not yet been studied for skidding operations is the quality of the work environment in terms of temperature and relative humidity, including their short-term variation. Both the ambient temperature and humidity 
are factors which affect human performance [17] and which may expose operators to serious disorders. Although the human body holds some adaptation capability to variations in temperature and humidity [17], daily temperature variability was found to affect people in regular setups, being a variable associated with mortality [11]. Seasonal variability in temperature was also found to be associated with contrasting results in mortality, with a change of $1^{\circ} \mathrm{C}$ being associated with an increase of $1 \%$ in mortality during summer [18]. Moreover, rapid changes in temperature within a day were found to be independent risk factors for human health. The review study of [3] has emphasized that daily temperature variability is associated with mortality and morbidity, particularly with cardiovascular and respiratory disorders.

Modern forestry machines are typically equipped with climate control technology, which is often missing or does not work on older-made machines. In addition, the degree to which such environmental control technology is used also depends on the operators' habits. Therefore, a characterization of the potential variability in daily temperature and humidity within the machine's cabin is important in order to understand the risk at which the operators are placed or are placing themselves by the level of technology made available to them and by their behavior in the workplace, respectively. In addition, it is important to check if there are any differences between these environmental parameters as an effect of different workplaces, namely inside a skidder's cabin and outside, in the forest environment.
The aim of this study was to characterize the skidding work environment (i.e., the machine's cabin) in terms of variability in temperature and relative humidity for two models of Romanian-made skidders, based on a representative sample in terms of operational conditions. The first objective of the study was to characterize the variability of the two micro-climate parameters relative to their variability in the forest work environment in order to emphasize the differences brought by the operations themselves and to understand the exposure of skidder workers relative to other kind of work developed in the forest (i.e., outdoors). The second objective of the study was that of independently characterizing the variability of the two parameters with the aim of understanding it in the context of the operations themselves.

\section{Materials and Methods \\ 2.1. Study Location}

Three forest districts were selected for field data collection activities. The selected forest districts (Table 1) are managed by the Maramureş Forest Directorate of the National Forest Administration - RNP Romsilva, which is located in the Northwestern part of Romania. Three forest compartments were designated as study locations (sites $S L 1-S L 3)$ and the operations were observed for a number of three operational days (observation days OD1$O D 3$ ) in the first two study locations and for one operational day in the last study location. The forests from the study area are located in the mountains and they are dominated by broadleaved species, typically by European beech (Fagus sylvatica L.); those fulfilling production 
functions are managed according to the implementation of selective extractions. close-to-nature principles, by the

Table 1

Summary description of the study location, machines used, and sampling days

\begin{tabular}{|c|c|c|c|}
\hline Forest district & Machine & Sampling days & Abbreviation \\
\hline \multirow{3}{*}{ Baia Sprie } & TAF 690PE & $10^{\text {th }}$ of November 2020 & SL1OD1 \\
\cline { 2 - 4 } & TAF 690PE & $11^{\text {th }}$ of November 2020 & SL1OD2 \\
\cline { 2 - 4 } & TAF 690PE & $13^{\text {th }}$ of November 2020 & SL1OD3 \\
\hline \multirow{3}{*}{ Mara } & TAF 657 & $11^{\text {th }}$ of November 2020 & SL2OD1 \\
\cline { 2 - 4 } & TAF 657 & $12^{\text {th }}$ of November 2020 & SL2OD2 \\
\cline { 2 - 4 } & TAF 657 & $13^{\text {th }}$ of November 2020 & SL2OD3 \\
\hline Groşii Jibleşului & TAF 690PE & $12^{\text {th }}$ of November 2020 & SL3OD1 \\
\hline
\end{tabular}

In general, broadleaved wood was extracted during the field study in the form of tree lengths. Extraction was done on considerable distances, reaching in some cases more than $2 \mathrm{~km}$. The typical work organization was similar to that reported in other studies $[1,2]$ and consisted of winching at the felling site, on-road skidding, and landing operations. Two skidder models were observed during the field study, namely a TAF 657 and a TAF 690PE (Table 1), and all the data supporting this study was collected in November of 2020.

\subsection{Experimental Design and Data Collection}

Data on air temperature $\left(T,{ }^{\circ} \mathrm{C}\right)$ and relative humidity $(\mathrm{RH}, \%)$ was collected in all the study locations and on all of the monitored operational days by means of six Extech $^{\circledR}$ RHT 10 temperature and relative humidity data loggers (Figure 1 ). Such miniaturized data loggers [4] enable accurate data collection at fine sampling rates ( 2 seconds), they are easy to handle, set up, and dismantle, and are supported by dedicated software which helps in programming a given data logging mission, downloading and saving the data along with date and time labels in computer-friendly formats such as Microsoft Excel $^{\circledR}$. On each day and for each study location, a pair of data loggers was used, one of which was placed on the North-facing direction of a tree (Figure 1a) located inside the forest at a distance of at least $25 \mathrm{~m}$ from the forest road (Control), and one (Actual) was placed inside the skidder's cabin, on the back side of the chair (Figure 1b). In each location and for each observation day, data loggers were set to collect data at a sampling rate of 2 $\mathrm{Hz}$, before placing them on the trees or inside the skidder's cabin. The reason for placing the data loggers on the northern side of the trees was preventing the direct incidence of solar radiation on the data logger [20]. Once these activities were done, skidding operations began and the data was collected for the entire day, which included rest and meal breaks. At the end of each day, the data was downloaded in a personal computer via USB ports, saved as Microsoft Excel ${ }^{\circledR}$ files, and organized according to study locations and days of observation. 


\subsection{Data Processing and Statistical Analysis}

Data from each study location and day of observation was paired based on the date and time labels. Then, the data coming from the two data loggers was plotted in the time domain to check it and to identify potential anomalies. Since it was not possible to start both data loggers at the same time, there were some lags between the two datasets in terms of time taken to start and stop data logging (Figure 2). As such, to support data analysis, the data logger setup and dismantling periods were considered to be those in which at least one data logger did not hold any recordings. Typically, the data logger placed and taken down from the trees was the one started and stopped later than that placed inside the skidder's cabin.

Since the data loggers were placed in the forest and in the skidder's cabin right after being taken from the car which was used for transport to the operation site, a time period was needed for stabilization between readings (mainly cooling down of the data loggers placed in the forest). This period was observed in graphs developed so as to resemble that shown in Figure 2, then the data was analyzed in detail to identify the first segment of constant readings after a steady decrement, and the transition points between the two were used as reference for data segmentation. In addition to those periods used for placing and taking down the data loggers, this period was removed from the datasets used as inputs for analysis. The rest of the data (Measure, Figure 2) was used for further processing and statistical analysis.

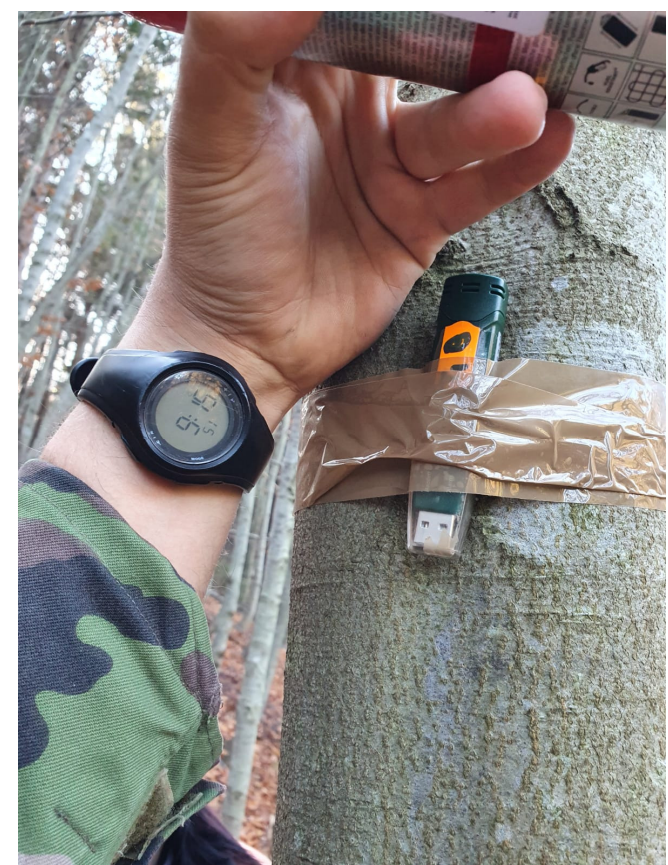

a

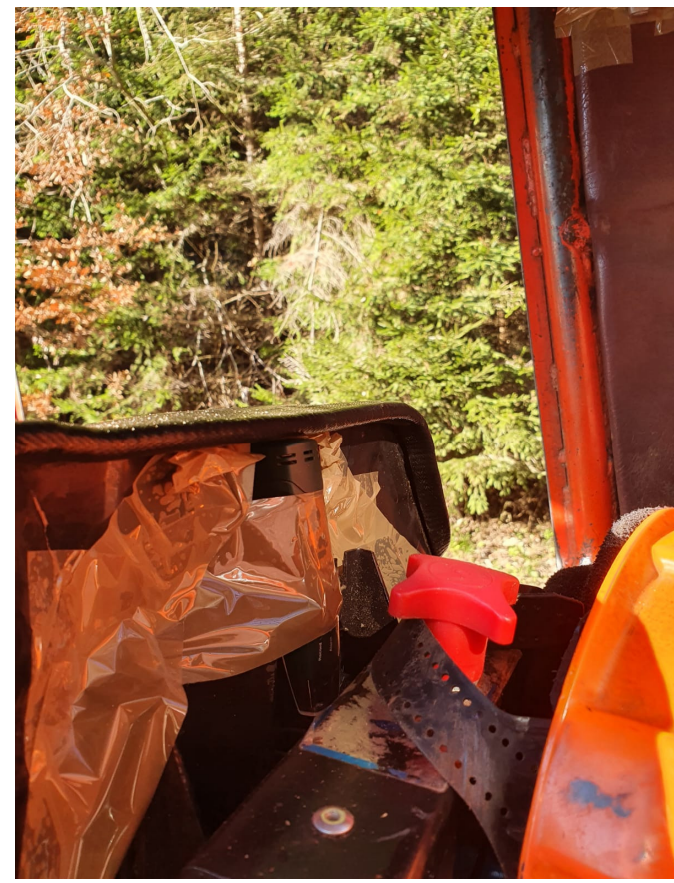

b

Fig. 1. Data loggers used and their placement on the trees (a) and inside the cabin (b) 


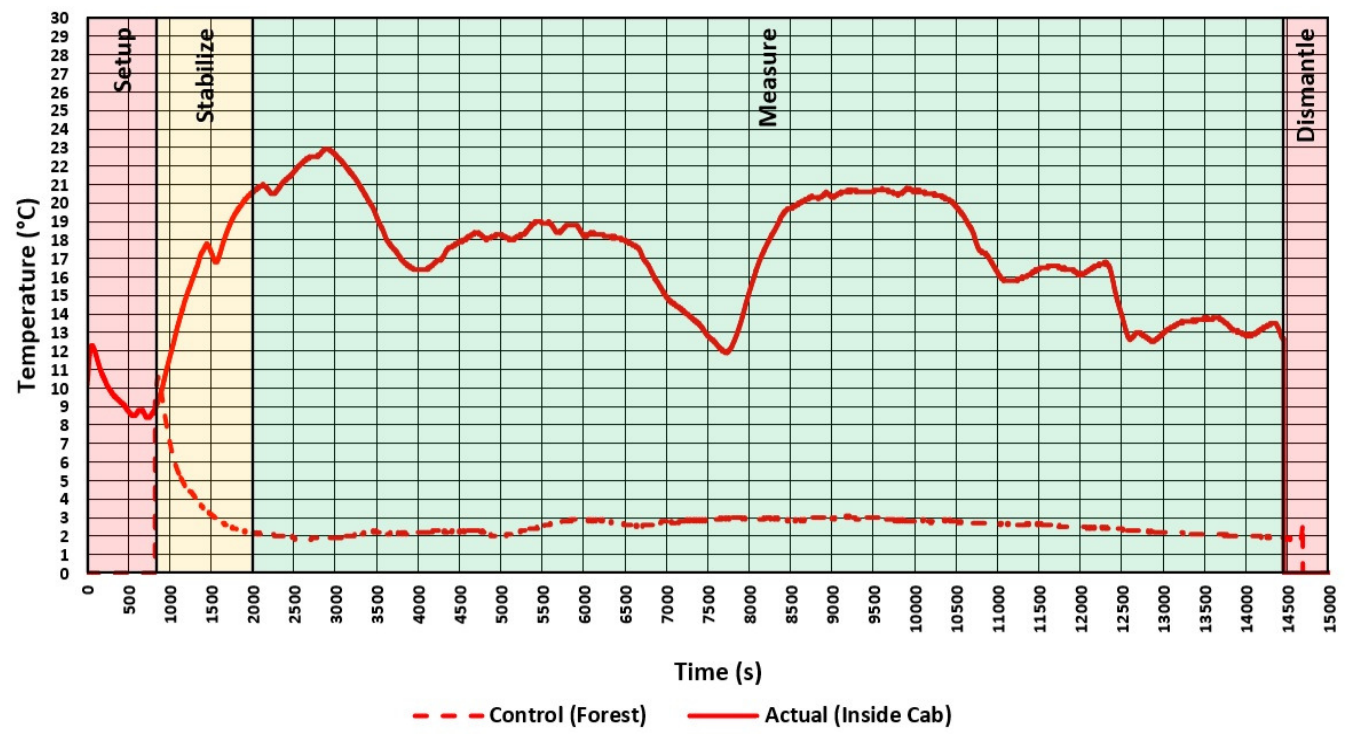

Fig. 2. Temperature data visualization (10 $0^{\text {th }}$ of November 2021, Baia Sprie) and steps taken to segment the data suitable for analysis: setup and dismantle - data removed from analysis due to missing points, stabilize - data removed from analysis due to erroneous readings of the data logger placed in the forest (cooling down), measure - data kept for analysis

For the first objective of the study, the data collected inside the skidders was processed to get the absolute positive difference $(\Delta)$ relative to the data collected in the forest. Equations 1 and 2 were used to calculate the differences in terms of temperature and relative humidity. The data processed this way was plotted in the time domain for each study site and operational day to reflect the variability for each condition.
Accordingly, the variability in differences was summarized by means of basic descriptive statistics reported in the form of boxplots. In addition to the data plotted for each study site and operational day, the differences were aggregated at the study level for both temperature and relative humidity. Summary boxplots were then prepared and reported for these study-level aggregated datasets along with those mentioned above.

$$
\begin{gathered}
\Delta T_{-} S L_{i k} O D_{j k}=\left|T C_{-} S L_{i k} O D_{j k}-T A_{-} S L_{i k} O D_{j k}\right|\left[{ }^{\circ} \mathrm{C}\right] \\
\Delta R H_{-} S L_{i k} O D_{j k}=\left|R H C_{-} S L_{i k} O D_{j k}-R H A_{-} S L_{i k} O D_{j k}\right|[\%]
\end{gathered}
$$

where:

$\Delta T_{-} S L_{i k} O P_{j k}$ is the absolute positive difference in temperature for each observation recorded at the time label $k\left(k=1\right.$ to $\left.N_{i j}\right)$ calculated for the study location $(S L) i \quad(i=1$ to 3$)$ and operational day $(O D) j(j=1$ to 3$)$; 
$N_{i j}$ - the number of observations recorded and used in the analysis for a given study site (i) and operational day (j);

$T C_{-} S L_{i k} O D_{j k}$ - the temperature recorded by the data logger placed on the tree (Control) for each observation recorded at the time label $k$, study site $i$, and operational day $j$;

$T A S L_{i k} O D_{j k}$ - the temperature recorded by the data logger placed in the skidder's cabin (Actual) for each observation recorded at the time label $k$, study site $i$, and operational day $j$.

The members shown in Equation 2 have the same meaning with the difference that temperature $(T)$ is replaced by relative humidity $(R H)$.

For the second objective of the study, the data collected inside the skidder's cabin was used in the format provided by the data loggers. This data was analyzed by means of plotting it in the time domain for each study site and operational day, in a way which was similar to that used for the first objective of the study. Then, the data was described by means of basic descriptive statistics in the form of boxplots. For both objectives, the graphs showing the variability in the time domain were developed to reflect a resolution in one hour which supported the interpretation and discussion of the results.

\section{Results and Discussion}

\subsection{Differences in Temperature and} Relative Humidity Compared to the Forest Environment

Figure 3 shows the absolute positive differences $(\Delta)$ in temperature and relative humidity between the forest environment and the skidder's cabin. In terms of temperature, such differences varied between ca. 1.5 and $21^{\circ} \mathrm{C}$, while in terms of relative humidity they varied between ca. 5 and $56 \%$.

Right from the beginning, it is worth mentioning that a control over the door state was not exercised in this study. Therefore, the data shown in Figure 3 stands for the free will of the skidder operators in what regards keeping the door closed at all times during the operations. In addition, the data also includes the measurements taken during the rest and meal breaks and it reflects several skidding cycles per study location and day of observation which supposed uphill and downhill driving on considerable distances and altitudinal ranges. The data coming from the control points, on the other hand, reflected the temperature and relative humidity recorded near the landing areas which were located, for each study site, downhill, near the forest roads. All these factors could have affected the variability found in the absolute differences as shown in Figure 3.

Also, as shown in Figure 3, there were both more or less contrasting, considerable and sharp variations in relation to the operation time. For instance, the differences in temperature for $\mathrm{SL2O3}$ presented a relatively constant dynamic in the timeline. These were in range of ca $1^{\circ} \mathrm{C}$. At the opposite side, SL1OD1 presented contrasting changes, with differences accounting for up to $10^{\circ} \mathrm{C}$ in less than an hour of observation. In addition, for SL2OD1, such differences accounted for 3 to $8^{\circ} \mathrm{C}$ and they occurred in less than 10 to 30 minutes. A similar dynamic was recorded for the data characterizing the differences in terms of relative humidity (Figure $3 b$ ). 


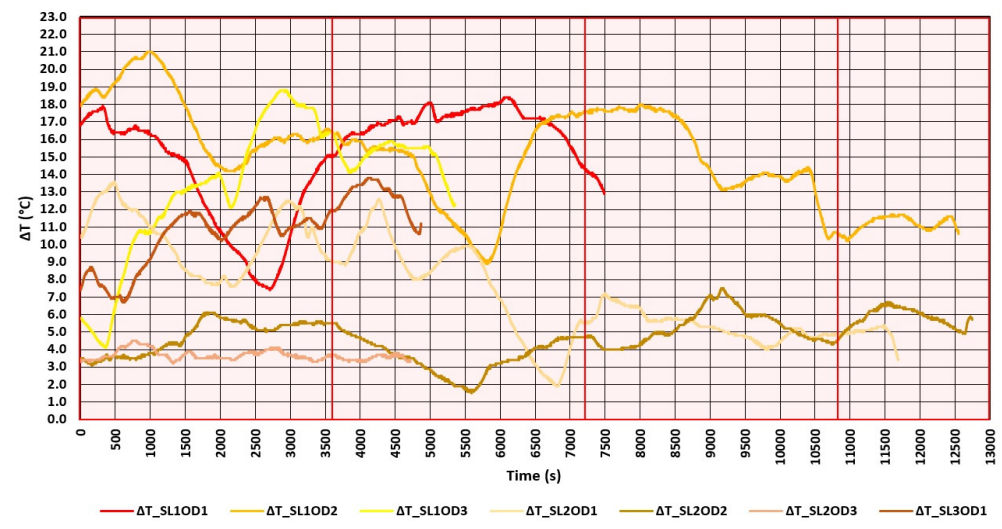

a

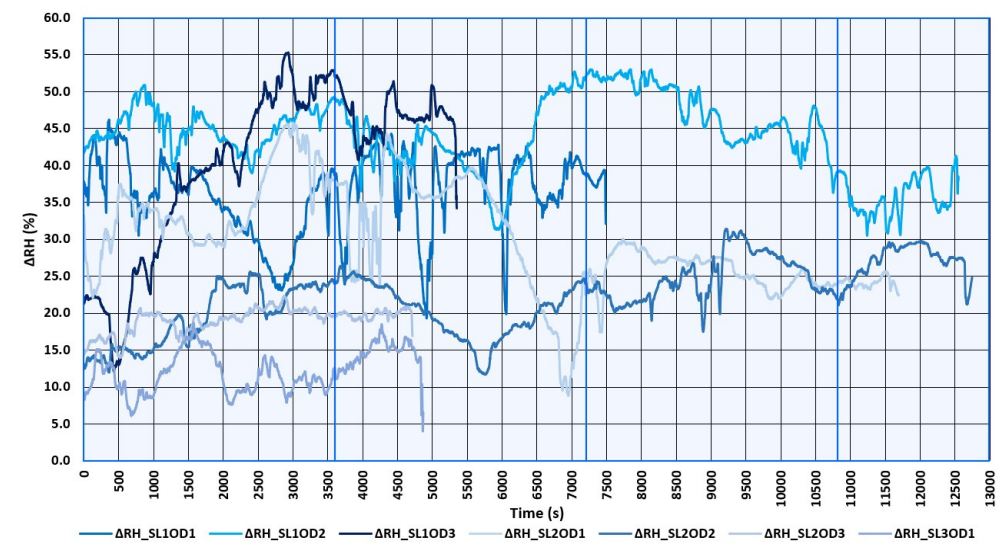

b

Fig. 3. Temperature (a) and relative humidity (b) differences between the forest (Control) and the skidder's cabin (Actual) for each study site and day of observation

Figure 4 , on the other hand, shows the descriptive statistics of the absolute positive differences in temperature and relative humidity at the study site and observation day level, as well as at the descriptive statistics which were developed based on data aggregated at the study level. The mean differences in temperature and relative humidity varied to a great extent depending on the study location and day of observation. On average, and depending on the study site and observation day in question, the mean differences in temperature were in the range of ca. 4 and $15^{\circ} \mathrm{C}$ in the skidders' cabins as compared to the control points (Figure 4a). The same figures for relative humidity were in range of ca. 12 and $44 \%$ (Figure 4b). Taken together at the study level, the differences in temperature averaged ca. $10^{\circ} \mathrm{C}$ (Figure $4 \mathrm{a}, \Delta T_{-}$Overall) while the differences in relative humidity averaged ca. $30 \%$ (Figure $4 \mathrm{~b}$, $\left.\triangle R H \_O v e r a l l\right)$. However, the temperature difference varied considerably at the study level between ca. 1.5 and ca. $21^{\circ} \mathrm{C}$, while the difference in relative humidity varied between ca. 5 and $56 \%$. 


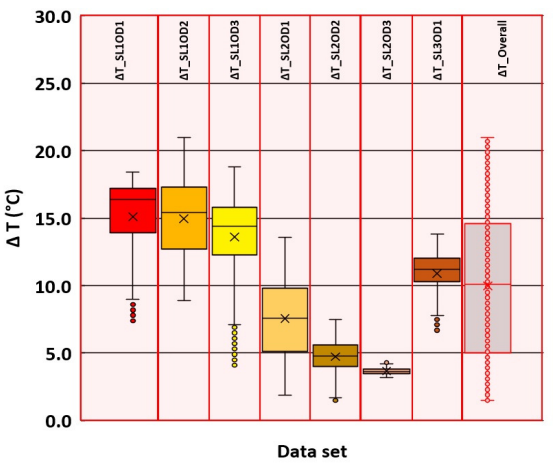

a

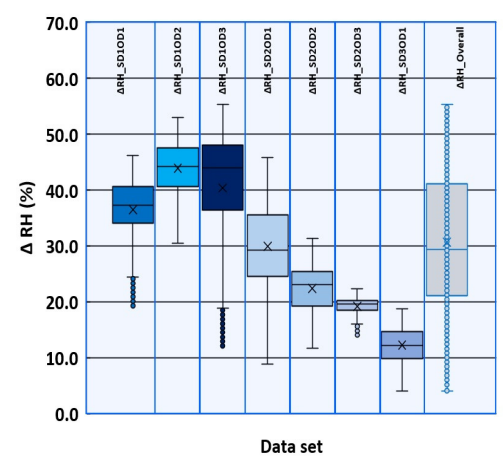

b

Fig. 4. Descriptive statistics of absolute positive differences in temperature (a) and relative humidity (b)

\subsection{Temperature and Relative Humidity in the Skidder's Cabin}

Variation in temperature and relative humidity measured as absolute values inside the skidders' cabins is given in the time domain in Figure 5. Since these parameters recorded at the control points showed a relatively constant dynamics (Figure 2), the variation shown in Figure 3 was mostly the effect of temperature and relative humidity dynamics in the skidders' cabins as shown in Figure 5.

The patterns shown here were similar to those of the differences presented in Figure 3 and the results found for this parameter are rather concerning. For instance, there were study locations and observation days (SL2OD3, SL3OD1) for which the inside temperature barely reached $9^{\circ} \mathrm{C}$ during a given observation day. In other cases, the inside temperature reached $25-26^{\circ} \mathrm{C}$, although it varied considerably within a given observation hour from ca. 15 to ca. $26^{\circ} \mathrm{C}$ (SL1OD1). Also, in some cases, significant variation was recorded for shorter time intervals. For instance, there were some study sites and observation days in which the differences were in range of 3 to $4^{\circ} \mathrm{C}$ in time periods shorter that 20 minutes (sometimes even shorter than 10 minutes). Similar patterns were found in the case of relative humidity, with the difference that positive and negative changes of 5 to $10 \%$ occurred in time intervals of less than 10 minutes (Figure $5 b$ ).

Summary statistics of temperature and relative humidity recorded inside de skidders' cabins are given at the study site, operational day, and study level in Figure 6. Depending on the study site and observation day, the mean values of temperature recorded inside the cabin ranged from ca. 6 to ca. $22^{\circ} \mathrm{C}$. In two cases, the observed mean temperature inside the cabin was lower than $10^{\circ} \mathrm{C}$, in three cases it was between 10 and $15^{\circ} \mathrm{C}$, and only in two cases it exceeded $15^{\circ} \mathrm{C}$. On average, the temperature recorded inside the cabin was ca. $13^{\circ} \mathrm{C}$, but it varied widely between ca. 3.5 and $25.5^{\circ} \mathrm{C}$. Relative humidity followed an inverse trend at the study site and observation day level and it averaged ca. $55 \%$ at the study level. However, it varied widely between ca. 34 and $89 \%$.

The variations shown in Figures 5 and 6 indicate the micro-climate conditions inside the cabins. Assuming the use of a 
climate control system, the expectation would be to have a small variability in temperature and relative humidity, which was not the case. However, the same limitations of the study as presented above should be mentioned here, namely the fact that it was not possible to remove from the study the time spent for resting and meal breaks. Nevertheless, the data presented in the results section stands for a good representation of the microclimate conditions of the skidders' cabins in terms of temperature and relative humidity during work.

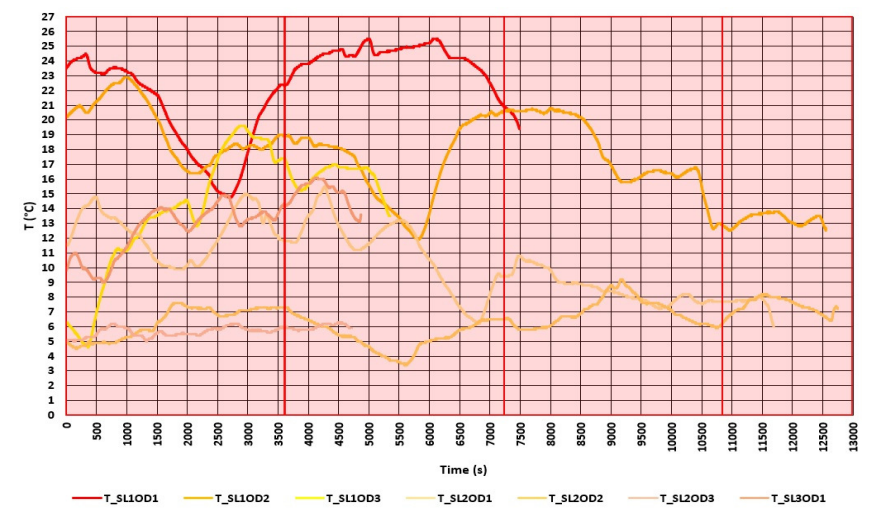

a

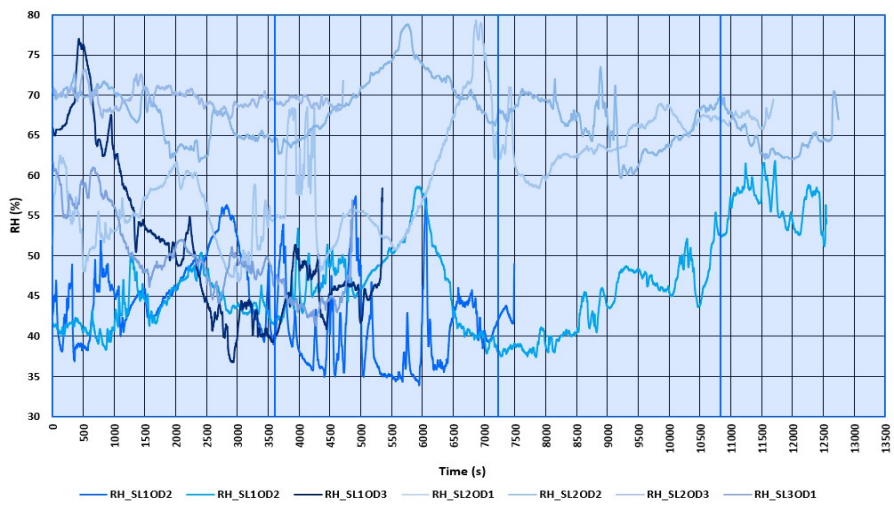

b

Fig. 5. Temperature (a) and relative humidity (b) inside the skidder's cabin

\subsection{Discussion}

Providing a safe and healthy work environment is of crucial importance for the performance of forest operations. This study evaluated the variability in temperature and relative humidity which stand for important parameters of the workplace microclimate in skidding operations. As found by this study, the outdoor environment of the forest provided less variability in temperature and relative humidity, generally placing it at high contrast with the data recorded in the skidders' cabins. However, the diurnal dynamics in temperature may change depending on season. For instance, in summer periods characterized by the 
absence of wind and a clear sky the diurnal temperature and relative humidity dynamics follow a bell- and " $U$ " shape respectively [20], therefore such seasons would typically modify the forest environment parameters as well as their relation to what happens in the skidder's cabin. From this point of view, as well as

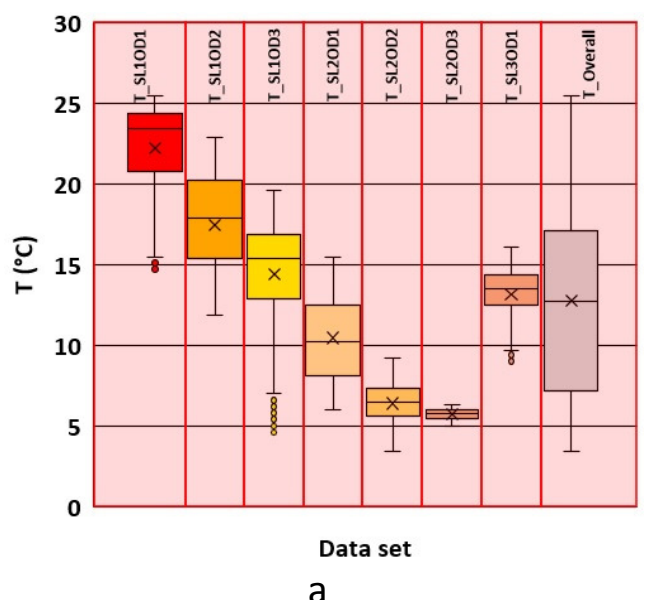

due to the fact that near the gaps in canopy the external environment changes in microclimate, more research is needed to clarify the effects on the skidder's cabin microclimate. To properly cover such variations, studies would probably need to be extended to the whole year.

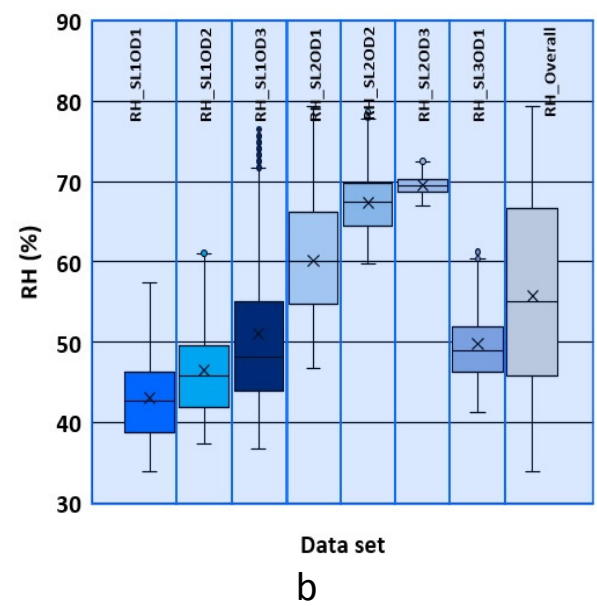

Fig. 6. Descriptive statistics of temperature (a) and relative humidity (b) inside the skidder's cabin

In this study it was impossible to control the behavior of the operators, specifically it was impossible to check if the cabin door was closed at all times during the operations. For this reason, as well as for reasons related to the inclusion of rest and meal breaks into the analyzed data pools, the figures given herein, even if they stand for a good approximation of the effects of environmental and operational conditions on the cabin's microclimate, should be interpreted as indicative. What can be speculated is that even if the workers left the cabins for some periods of time, in fact they exposed themselves, in many cases, to even more contrasting values of temperature and humidity. In most cases, variations in temperature and humidity inside the cabin were found to vary considerably in short periods of time. The cofounding factors that could have contributed to such dynamics might be the operational behavior, environmental characteristics (i.e., gaps in the canopy, variations in temperature and humidity in different operation places for the same machine and study site), factors related to the machine (heating up due to the engine's operation), and mobility of the machine (i.e., operation on high distances and considerable altitudinal ranges). Independent contributions of the abovementioned factors to the variability in temperature and humidity were not possible to quantify in this study, a fact that also may guide possible experiments to be developed in the future. First of all, a 
control over the cabin door needs to be exercised, at least by a documentation of those time periods in which it was open. Secondly, detailed information on the presence of the driver in the cabin would be essential to better understand the exposure, the same way in which a detailed documentation of the functional steps taken during the operation would contribute to a better interpretation of the data.

Placing a data logger to collect control data as described in this study helped considerably in determining potential differences between what could happen inside and outside the skidders' cabins. However, as the skidders are characterized by mobility, it would be appropriate to place a data logger in the machine to collect such control data outside the cabin, thus also enabling the mobility of the control data. Such an approach, if coupled with recorded GPS locations and a description of functional steps taken into the operations would be of great help in better understanding the changes that may occur in the microenvironments of the skidders' cabins.

To what extent the operators are adapting themselves to such variations in temperature and humidity and the extent to which such working conditions would affect their health need to be questioned, probably by running epidemiological studies in addition to quantifying microclimate variables. In this regard, a similar study [9] pointed out that microclimate variables were found in their limits for wood extraction operations by skidders. Still, the same authors stated that nearly one third of the observed workers were found to suffer from occupational diseases, namely osteomusculoskeletal, heart, and respiratory conditions. Indeed, it is highly challenging to bring forward data on what would be the temperature and relative humidity at which different persons feel comfortable, and temperatures of $20-24^{\circ} \mathrm{C}$ are considered suitable for indoor environments during winter [8]. For this reason, many judgments are made based on the available legislation, although workers in forest operations still suffer from various disorders [5, 6], [9]. From these points of view, the variability and magnitude shown by the results of this study on temperature and relative humidity may be of concern for the health state of the skidder operators. Still, to conclude on the dynamics of such parameters and to get an overview all seasons, more research is required. Updating the climate control systems in such machines or replacing the older skidders with newer models would be useful steps to improve the working conditions of skidder operators. Also, proper compensation for these workers would be in question given the quality of the environment in which they are required to operate. Regular trainings would also help in preserving better working environments by instructing the operators on the measures to be taken during their work.

\section{Conclusions}

Our results indicate evident and contrasting differences in terms of temperature and relative humidity between the skidders' cabins and the forest environment. These differences were driven mainly by the operation of the skidder and probably by the work behavior and the local environmental conditions of the workplace, since 
skidding involves mobility. Inside the skidders' cabins highly contrasting variations were found to occur in short periods of time, and in some cases the recorded temperatures were very low. Given the results and the season in which the data was collected, as well as other constraints of the study such as using the control data from a fixed point, further studies should be carried out to delimitate the operation time from the rest and meal breaks, to evaluate the variability in microclimate throughout all the seasons, to control the state of the cabin doors, and to solve the problem of control data mobility to accurately reflect the outdoor conditions for each location a skidder may work on during the operation.

\section{Acknowledgements}

This paper was supported by research grant No. 4522/14.05.2020 - Studiu privind stabilirea consumurilor de combustibili şi a normelor de timp şi productie în activitatea de colectare a lemnului ca urmare a modernizării parcului de utilaje al unităților regiei, financed by the National Forest Administration - RNP Romsilva. The authors acknowledge the logistical support of the Department of Forest Engineering, Forest Management Planning and Terrestrial Measurements, Faculty of Silviculture and Forest Engineering, Transilvania University of Brasov. Also, the authors would like to thank the management of the National Forest Administration and the management of Regional Forest Directorate of Maramureş for logistically supporting this study in the field phase.

\section{References}

1. Borz S.A., Dinulică F., Bîrda M. et al., 2013. Time consumption and productivity of skidding Silver fir (Abies alba Mill.) round wood in reduced accessibility conditions: a case study in windthrow salvage logging from Romanian Carpathians. In: Annals of Forest Research, vol. 56(2), pp. 363-375. doi: 10.15287/afr.2013.38.

2. Borz S.A., Igne, G., Popa B. et al., 2015. Estimating time consumption and productivity of roundwood skidding in group shelterwood system - a case study in a broadleaved mixed stand located in reduced accessibility conditions. In: Croatian Journal of Forest Engineering, vol. 36(1), pp. 137-146.

3. Cheng J., Xu Z., Zhu R. et al., 2014. Impact of diurnal temperature range on human health: a systematic review. In: International Journal of Biometeorology, vol. 58(9), pp. 20112024. doi: 10.1007/s00484-014-0797-5.

4. Extech RHT10 data loggers. Available at: http://www.extech.com/ products/RHT10. Accessed on: December 5, 2021.

5. Gallis C., 2006. Work-related prevalence of musculoskeletal symptoms among Greek forest workers. In: International Journal of Industrial Ergonomics, vol. 36(8), pp. 731-736. doi: 10.2016/j.ergon.2006.05.007.

6. Grzywinski W., Wandycz A., Tomczak A. et al., 2016. The prevalence of selfreported musculoskeletal symptoms among loggers in Poland. In: International Journal of Industrial Ergonomics, vol. 52, pp. 12-17. doi: 10.1016/j.ergon.2015.07.003. 
7. Heinimann H.R., 2007. Forest operations engineering and management - the ways behind and ahead of a scientific discipline. In: Croatian Journal of Forest Engineering, vol. 28(1), pp. 107-121.

8. Helander M., 2006. A guide to human factors and ergonomics. $2^{\text {nd }}$ Edition. Boca Raton London New York, CRC Press Taylor \& Francis Group, 414 p.

9. Iftime M.D., Dumitrascu A.E., Dumitrascu D.I. et al., 2020. An investigation of major physical hazard exposures and health effects of forestry vehicle operators performing wood logging process. In: International Journal of Industrial Ergonomics, vol. 80, 103041. doi: 10.1016/j.ergon.2020.103041.

10. Lundbäck M., Häggström C., Nordfjell T., 2021. Worldwide trends in methods for harvesting and extracting industrial roundwood. In: International Journal of Forest Engineering, vol. 32(3), pp 1-14. doi: 10.1080/14942119.2021.1906617.

11. Ma C., Yang J., Nakayama S.F. et al., 2019. The association between temperature variability and causespecific mortality: Evidence from 47 Japanese prefectures during 19722015. In: Environment International, vol. 127, pp. 125-133. doi: 10.1016/j.envint.2019.03.025.

12. Marchi E., Chung W., Visser R. et al., 2018. Sustainable Forest Operations (SFO): a new paradigm in a changing world and climate. In: Science of the Total Environment, vol. 634, pp. 13851397. doi: 10.1016/j.scitotenv. 2018.04.084.

13. Moskalik T., Borz S.A., Dvořák J. et al., 2017. Timber harvesting methods in Eastern European countries. In:
Croatian Journal of Forest Engineering, vol. 38(2), pp. 231-241.

14. Oprea I., 2008. Tehnologia exploatării lemnului (Wood exploitation technology). Transilvania University Press, Brasov, Romania, $273 \mathrm{p}$.

15. Poje A., Potočnik I., Danilović M. et al., 2016. A case study on the impact of skidding distance on tractor operator exposure to noise. In: Baltic Forestry, vol. 22(2), pp. 357-364.

16. Potočnik I., Poje A., 2017. Forestry ergonomics and occupational safety in high ranking scientific journals from 2005-2016. In: Croatian Journal of Forest Engineering, vol. 38(2), pp. 291-310.

17. Rodahl K., 1989. The physiology of work. $1^{\text {st }}$ ed. Taylor and Francis, CRC Press, London, England, $296 \mathrm{p}$.

18. Shi L., Kloog I., Zanobetti A. et al., 2015. Impacts of temperature and its variability on mortality in New England. In: Nature Climate Change, vol. 5(11), pp. 988-991.

19. Spinelli R., Magagnotti N., Visser R. et al., 2021. A survey of skidder fleet of Central, Eastern and Southern Europe. In: European Journal of Forest Research, vol. 140(10), pp. 901-911. doi: 10.1007/s10342-021-01374-z.

20. Tiţă G.C., Marcu M.V., Ignea G. et al., 2019. Near the forest road: small changes in air temperature and relative humidity in mixed temperate mountainous forests. In: Transportation Research. Part D Transport and Environment, vol. 74, pp. 82-92. doi: 10.1016/j.trd.2019.07.016. 